\title{
Neglected Pragmatism: Discussing Abduction to Dissolute Classical Dichotomies
}

\author{
Alger Sans Pinillos ${ }^{1}$ iD
}

Accepted: 30 August 2021 / Published online: 6 September 2021

(c) The Author(s) 2021

\begin{abstract}
Many parts of the contemporary philosophical debate have been built on the radicalization of conclusions derived from the acceptance of a certain set of classical dichotomies. It also discusses how pragmatism and abduction are currently presented to solve the problems arising from these dichotomies. For this reason, the efforts of this article have been directed to analyze the impact of this fact on the philosophy of science and logic. The starting point is that accepting abduction implies, in many ways, accepting the foundations of pragmatism. Also, that the analysis of such problems from pragmatism and the particular use of abduction dissolve the dichotomies and, with it, also modify the philosophical problems related to them. Therefore, I propose to understand abduction as the right conceptual device to review the problems and debates of the twentieth century's epistemology from a pragmatic perspective. In doing so, the aim is to propose that the current use of abduction in contemporary debates may imply a change of the philosophical perspective.
\end{abstract}

Keywords Abduction · Dichotomy · Pragmatism · Philosophy of science

\section{Introduction}

Set against these the slogans implicit in the lower, popular utilitarianism. "I show you sorrow" (the world as it is now) "and the ending of sorrow" (the world as it will be when Progress and a few more indispensable wars, revolutions, and liquidations have done their work). and then, "Seek ye first all the rest-creditable virtues, social reform, instructive chats on the radio and the latest in scientific gadgets"-and some time in the twenty-first or twenty-second century the kingdom of God will be added. Aldous Huxley, 1948: 274)

This paper shows that, while abduction and pragmatism are increasingly important today, their inseparable nexus is still disregarded. One can realize this fact by seeing how the paths of these two issues have diverged in the philosophy of science debates of the past

Alger Sans Pinillos

alger.sanspinillos@unipv.it

1 Department of Humanities, Philosophy Section, University of Pavia, Pavia, Italy 
mid-century. As West said in the late 1990s, the interest in pragmatism has been only and especially active in areas of knowledge such as comparative literature, historical criticism, and others (West, 1989: 3). In these disciplines, abduction is disregarded, and pragmatism is merely understood as the meta-perspective that establishes the basis for the world's experimentation in the communicative reaction (Cooren, 2014).

The problem is that when we accept the pragmatist point of view, we should also develop a commitment to its ontology and epistemological assumptions. These assumptions are:

(1) This theory assumes that the experience configuring reality is structured from a continuous flux of information (world of pure experience).

(2) Continuous experience maintains knowledge in a certain degree of provisionality, which obliges us to revise and adapt our beliefs to the changes we experience (fallibilism).

The problem is that, while the first assumption is accepted, the second is not. Although the contextuality of the practical dimension of research is accepted in terms of contingency, neither individual indeterminacy nor the epistemological role of the community is assumed (Bergman, 2012). More specifically, the problem is that there remains a classical conception of the subject, in which doubt and knowledge are individual. One of the reasons for this may be the type of pragmatism that is taken to be theorized, for example, Rorty's relativistic $^{1}$ type (Sundin \& Johannisson, 2005). Of course, the problem of relativism is not discussed in these debates.

This case shows that, although pragmatism is often touted as a reform of old problems, the scale of this claim is not fully understood. We perfectly know that pragmatism dissolves some of the fundamental problems of philosophy thanks to the "practical" point of view of the investigation. However, such interpretations tend to draw very generally, sometimes overly exaggerated, ideas from pragmatist consequences or statements. One of the reasons is the constant neglect of the importance of the relationships between pragmatist epistemology and logical problems concerning the representation of scientific practice: indeed, the pragmatist philosophical project considers theory and practice as interrelated.

The consequence of this conceptual situation is that the uses and results of scientific practices are assumed not to reflect the philosophical perspective offered by pragmatism. The other side of this situation lies in the conception of scientific practice assumed today, which often fails to consider the context in which it is developed: the objectivity is conceived in terms that are detached from the contingencies produced by the intrusion of the contextual aspects.

For this reason, the rise of pragmatism in fields such as epistemology has meant an attempt to solve certain dead ends. It is interesting to note that part of this strategy is caused by a rejection of specific ideas of pragmatism and that, therefore, it should not be assumed so quickly that its application implies a solution. On the contrary, it may uncover the philosophy inherited from logical empiricism that underpins the image of scientific practice. This is Hintikka's critique when he claims that abduction is a "fundamental contemporary

\footnotetext{
1 If we consider Rorty's epistemology from his ontology, it would be much more accurate to refer to his approach as a perspectivism type of anti-essentialist panrelationalism (Brown, 2020: 48).
} 
problem for epistemology" (Hintikka, 1998). Why abduction? The answer is obvious to anyone engaged in research in epistemology, cognitive science, philosophy of science, computational science, logic, and $\mathrm{AI}^{2}{ }^{2}$

The unification of research in cognitive science and AI has made it possible to conceptualize the role of heuristics in the discovery process, both from an algorithmic and a human reasoning perspective. Abduction has been a critical piece in this research, representing the inference proper to the hypothesis (Thagard, 1988: 51-52). Likewise, robotics research has brought to the table issues related to embodiment, action, situatedness, and manipulation of external entities appropriately cognitively reshaped (Magnani, 2019: sect. 1.1; Müller \& Hoffmann, 2017). On the other hand, the possibility of automating heuristic processes through the translation of their inferential processes into algorithms made it possible to think of the possibility of designing discovery machines such as, for example, the BACON programs (Simon et al., 1997). A still-open debate is whether the discovery characterized by these arguments exhausts the whole dimension of this process. For example, even if these machines can "discover" by reformulating accumulated information, it would seem that they cannot account for a genuine or entirely new creativity (Boden, 2004: Ch. 8).

The differentiation between discoveries resulting from a reinterpretation of data and genuine discovery can be better understood by conceptualizing such processes through abduction. Drawing from the Eco-Cognitive Model of Abduction (EC-Model), ${ }^{3}$ it can be observed that creativity occurs in many different ways and with different nuances, depending on the context in which the process is taking place (Magnani, 2017). For example, in programs such as BACON, creativity is only characterized in terms of "sentential abductions" (the abductive process focused on verbal/symbolic inferences to evaluate hypotheses from the sentential form of the language with which it operates) (ibid., 216). On the contrary, they are incapable of generating content when there is no prior data or, in other words, when there is an absolute novelty. In the same way, they are also unable to interpret factors that are not translatable into data that can be compared with the information background. An example from machine learning theory would be the confusion between preferences and values when we want to get moral machines (Sans \& Casacuberta, 2019).

Abduction has emerged as a new working tool to address different contemporary problems as innovation and hypothesis generation and selection. In addition, abduction emerged as a tool to articulate the problem of discovery in the epistemological debates. These debates took an unexpected turn with the computational paradigm, as it offered tools to formalize ampliative inference. Moreover, an argument against the dichotomy between psychological and logical facts was presented from a renovated new perspective. Abduction is related to a method problem, but the pragmatist halo of this important concept is lost.

We have to add that the question of what I will call the collapse of dichotomies ${ }^{4}$ has not impacted debates in the philosophy of science and epistemology. As already mentioned, this has generated a curious situation: On the one hand, pragmatism has become known through abduction, but, paradoxically, this concept has been applied in debates that do not

\footnotetext{
2 The contemporary problem stated in the text acquires a different meaning within Hintikka's analysis of the state of contemporary epistemology in one of his later works, where this same text is reprinted under the title "Abduction-Inference, Conjecture, or an Answer to a Question?" (Hintikka, 2007: Ch. II, 38-60).

3 The reason for choosing the EC-Model is its contextualized application of abductive processes. In this way, comparing machine-made processes with those performed by a human being without any discrimination between them is necessary.

${ }^{4}$ Of course, the collapse of dichotomies is based on and inspired by Putnam's book (2002).
} 
include pragmatist principles. Proof of this is that, actively or passively, the dichotomous tradition is still maintained.

On the other hand, theories that defend a pragmatist starting point do not use abduction. This article takes this point as the beginning of a reflection: it establishes that the permanence of the dichotomies I will present below signifies that accepting both abduction and pragmatism implies an epistemic and cosmological shift. In other words, it establishes that abduction, as the touchstone of pragmatism, should acquire a whole new theoretical dimension that, once activated, can offer a reinterpretation of many contemporary philosophical problems. As I will try to show in this article, the reasons for taking this point of departure have to resort to the fact that the last dichotomy of the XXth century, the distinction between justification and discovery, represents a kind of culmination of an entire century of dichotomies. The main reason is that pragmatism was born precisely as a philosophical system that works from deconstructing the most celebrated dichotomies of the philosophical tradition.

One of the conclusions drawn at the end of this article is that the "pragmatization" of the worldview has begun to modify the perspective of the philosophy of science. Proposing abduction for this purpose implies taking up the classical debate of Pragmatism and, in turn, the value of abduction to bring down certain dichotomies. The last consequence of this assertion is only presented in this article by way of annotation. It is related to the consideration of abduction as a mechanism for interweaving the different dimensions of human reasoning, which had been logically and theoretically separated.

\section{The Dichotomal Century}

As is well known, two important debates shaped the philosophy of science in the last century: the problem of incommensurability and the problem of discovery. Traditionally, Reichenbach's theory of justification is regarded as the initiator of the separation between these two concepts (Reichenbach, 1951), mainly based on Comte's positivism. However, this theoretical rupture is not directly connected to the question of discovery but is derived from Frege's dichotomy between psychology and logic, which will be addressed in Sect. 2.2.

The relationship between these two dichotomies allows for a better understanding of the debate in the philosophy of science, in which the question of discovery was a theoretical necessity impossible to be conceptualized based on the established criteria of verification. The central issue was to define what discovery is when the only acceptable answer had to be formulated logically. In turn, this theoretical impossibility clashed directly with scientific evidence. The central themes of paradigm shift and incommensurability are proposals for reading the history of ideas as conceptual revolutions - nurtured by discoveries-rather than evolution. This made it possible to understand each historical moment as a paradigm in which scientific rigor operated with specific tools based on a particular worldview. 


\subsection{First Dichotomy: Justification/Discovery}

Although the different ways of approaching this situation shaped the positions known as the Received View (the supporters of justification) and the Neglected View (the sympathizers of discovery), the debate must be read from the synergies generated between the two positions. It should be noted that it is not as simple as it seems to place the participants in this debate in one place or the other. For example, although Feyerabend and Lakatos may have been followers of Popper, it is well known that this changed in the early 1970s. The reason for considering Lakatos in the received view and Feyerabend in the neglected one is not an acceptance or rejection of the discovery but their views on the criterion of verification.

Lakatos' classification of certain theories as pseudo-scientific is a sign of his attachment to the verifiability criterion, while the addition of irrational criteria through epistemological anarchism places Feyerabend in the opposite position. However, the controversial point here is not "irrationality" but the incorporation of elements that are not susceptible to description and/or formalization. An interesting case to mention is the contrast between Hanson's semantic theory-ladenness and Kuhn's historical-theoretical one. The inclusion of both Feyerabend and Hanson in the neglected view bag lies because the highlighted elements were based on psychologistic assumptions. The problem was not to identify the process of discovery with psychological elements but to assume that they were at work in the process of justification.

This critique of scientific monism was directed at the logicist reduction of the positivist program for two reasons: (1) because it could not account for historically relevant factors for both discovery and justification, and (2) because it did not accept contemporary emerging disciplines, which were largely based on those denied elements.

For this reason, Lakatos' Research Programmes attempt to converge different scientific models coexisting at a given historical moment without disregarding non-linear epistemic progress through the evolution of theoretical applications (Lakatos, 1978). However, in Lakatos' proposal, the idea of scientific progress that discriminates between different practices through the demarcation between pseudoscience and science persists. The same is true of Kuhn's work, which shows that the discussion was ultimately about how to complement Popper's critical realism through the social perspective of science and historical analysis. The perspective of these authors was the presentist characteristic of whig history ${ }^{5}$ (Butterfield, 1965: 9), in which the standard of rationality for assessing the evolution of a scientific theory would be the current state of the art thus reinforcing the image of scientific progress.

Laudan is the one who continues with this way of interpreting the problem of discovery. However, his proposal is an alternative way of substantiating scientific progress without resorting to Popper's idea of the solution of problems or Lakatos' classification of pseudoscience. His theory is based on a dialectical movement between the accumulation of evidence (perceptual) and problem-solving (conceptual). A strong point of his proposal is defining the problem as a concept loaded with meaning, which is transmitted historically (Laudan, 1980). The strength of his proposal is that, without dispensing with rationality, he disassociates rationality from historical temporality, or, in other words, that the content

\footnotetext{
5 Whig history is a historiographical perspective in which the past is conceived as a teleological process in which the ultimate goal is an institutional government that guarantees the liberties of individuals living together in society. This social progress is usually assumed to go hand in hand with scientific development.
} 
of rationality has varied over time. (ibid.: 54). An interesting proposal to explain change throughout history is Hesse's imagination-based theory (Hesse, 1954), based on a universal scientific language (Fernández Buey, 2004: 70). The articulation of this imagination is grounded on the fact that a confirmed theory can predict untested results by analogy with similar confirmed cases of the same theory (Hesse, 1966). Although there is an almost "romantic" insistence on defending rationality by intertwining the question of justification with historical and social elements, it is also true that the door was opened to contemplate the results of disciplines affected by these problems, such as economics and in general human sciences. More recent versions of the philosophy of science still based on the dichotomy between justification and the context of discovery attempt to reconcile the two elements by modifying the concept of justification. One example, still rooted in the idea of progress linked to a conception of rationality, is Kuipers' concept of evaluation (Kuipers, 2000). The project of removing the connotation of success from the current state of research changes the context of discovery to appreciation and makes it operate alongside that of the invention one (Musgrave, 1989: 20).

So far, (1) the problem of incommensurability and demarcation and (2) the discovery problem have been presented and related to the historical and social study of science. However, as already said above, this path was based on maintaining certain assumptions characterized by the tradition of positivist epistemology. The reason for this, we said, lies in the "presentist" approach to scientific development. Two more points remain to be considered and, to do so, it is necessary to bear in mind that, apart from the problem of historical approach on the part of the philosophers of science of the time, this was also biased, in the sense of considering only physics, mathematics and, in general, any scientific discipline that could be formally described (ergo, formally self-justified). The third front that appeared was the redefinition of induction based on the new computational science.

A classic example is Simon's project to refute Popper's conception of discovery through science by showing the possibility of describing heuristic information and thus being able to formalize synthetic knowledge (Simon, 1985). Another case is Harman's attempt to solve the Gettier Cases by differentiating classical, enumerative induction from general induction, which involves heuristic assumptions (lemmas) (Harman, 1965). The latter two cases are relevant for two reasons. First, through them, it is shown a tendency to give importance to heuristic relational strategies to characterize synthetic reasoning, and, second, both proposals are deficient. Simon's problem is that his "new" induction could be translated computationally (e.g., Simon's BACON programs introduced in sec. 1 above) and account for discovery through creative processes.

The problem with this whole trajectory leads back to the same place, to the moment when the dichotomous distinction between logic and psychology is made. Initially, this problem resulted in avoiding the psychological question by rejecting the relevance of the discovery because of the impossibility of formalizing it. Nevertheless, when this possibility seemed to emerge, it was realized that what was considered psychological did not encompass the whole social, cultural, and historical dimension precisely because of the prejudice that the discovery process had to possess causal power comparable to the deduction.

\subsection{Second Dichotomy: Logic/Psychology}

As explained above, the dichotomy between discovery and justification stems from another postulated earlier, which logically separates logical and psychological facts. Although this dichotomy can be observed with different nuances in positivist epistemology, Vienna 
Circle ontology, and even in Wittgenstein's Tractatus, it is quite assumed that its origin is in Frege (Thagard, 1988: 7; Nöhler, 2004: 151; Magnani, 2007: 278; Gabbay \& Woods, 2005: 2):

The word "true" indicates the aim of logic as does "beautiful" that of aesthetics or "good" that of ethics. All sciences have truth as their goal; but logic is also concerned with it in a quite different way from this. It has much the same relation to truth as physics has to weight or heat. To discover truths is the task of all sciences; it falls to logic to discern the laws of truth. The word "law" is used in two senses. When we speak of laws of morals or the state we mean regulations which ought to be obeyed but with which actual happenings are not always in conformity. Laws of nature are the generalisation of natural occurrences with which the occurrences are always in accordance. It is rather in this sense that I speak of laws of truth. This is, to be sure, not a matter of what happens so much as of what is (Frege, 1956: 289).

This dichotomy starts from the idea that the basis of epistemology is scientific knowledge, which is only possible to acquire through a process of description (Kieseppa, 1996: 70; Magnani, 2014: 287; Niiniluoto, 2014: 378). As is known, Frege's first motivation was to depsychologize logic (Bäckström, 2017). However, considering the general idea of mathematics and its possibility of being reduced to logic, expanding this conception to the rest of scientific research (Woods, 2013: 16-29n). Following the Aristotelian trend, ${ }^{6}$ Frege considered the psychological aspect of inquiry as intuition that realizes a pre-scientific moment since it could not be formalized. From this conclusion derives that the psychological dimension had no relevant epistemic value.

Frege's project was to define a concrete field for logical research. The fundamental problem was not so much psychology but the set of theoretical presuppositions that allowed "logical" conclusions to be drawn from non-logical questions. This problem had already been detected earlier. An example is Łukasiewicz's analysis of Aristotle's Principle of Contradiction, from which metaphysical questions are derived that allow ethical questions to be logically inferred (Łukasiewicz, 1971). Frege's project is also ontological in its postulation of a dichotomy. The tradition Frege starts from is studying physical laws relating to gnoseology through the end of the eighteenth century's logic. An example would be Mill's Methods, which logically formalizes induction (Mill, 2002: Sects. III, Ch. VIII). It is interesting to remember that Mill's work is motivated by Leibniz's calculus racionitator, which was based on the characteristica universalis of logic as the universal language to express the whole dimension of reality, including the causal one.

The reason for bringing up the calculus racionitator here is to trace the origins of synthetic reasoning and point out the basis on which Frege drew his dichotomy between logic and psychology. In the Begriffsschrift, Frege based the calculus rationitator on the characteristica universalis (Kluge, 1980: 141). This included the whole of logic as an analytic and universal language, the proof of which was contained in the same set. The importance of Frege in the subject that concerns us in this section is his circumstantial relevance for the universal logical validity (later, also mathematical), and the reason how the question of discovery in the middle of the last century implied a change in the meaning of it (Kluge,

${ }^{6}$ Either by direct reading or by tradition received through education. 
1980: 142). ${ }^{7}$ The general reason for this change lies in the transition from the infallibilist conception of knowledge to a fallibilist version. This change began when the discovery was understood under the hypothesis conception of the philosophy of science.

As we will see in the next Sect. 2.3, when Frege posed his dichotomy, the pragmatic alternative already existed, which established abduction as the logical form of synthetic reasoning, and Peirce's epistemological proposal was already a kind of fallibilist rationalism. However, Frege's work allowed Popper to base his theory on critical rationalism, which related the criterion of falsifiability to the validity of logic through the positivist view of understanding scientific research.

\subsection{Third Dichotomy: Analytic/Synthetic}

The version of the dichotomy between logical facts and psychological facts that defined the philosophy of science in various decades of the last century was filtered through the way logical Positivism had turned the traditional dichotomy between synthetic judgments and analytic judgments. As is well known, analytic truths are those that are true because of their form. One classic example is "All triangles have three angles". The two propositions are true by virtue of their form. In other words, a true universal description is contained therein. Otherwise, there are synthetic truths, which are circumstantial in the sense that they depend on the contingent form in which the facts are arranged. However, they are thought of as the only truths that provide some knowledge.

The formulation of this dichotomy is Hume's empiricist version, which focused on undoing the metaphysical links that guaranteed immutable truth and instead on creating new ones in between individual experimentation results and their collective weight in society through deliberation. In other words, with enlightened empiricism, the doors were opened to build updated theories of knowledge. With Hume, we find the most sophisticated and radical version of this position. However, we also find the problem that empiricism had not been able to solve: to explain the foundation of mathematical certainty without the exclusive dependence on the relation of ideas (Hume, 2009, Bk. I: III Sect. I, 121).

Later, in An Enquiry Concerning Human Understanding, Hume opens a sophisticated version of the dichotomy that would define empiricism, distinguishing logically between analytic judgments and synthetic judgments based on the categorical distinction between a priori and a posteriori judgments. Within this perspective, mathematics was understood as forms by relations of ideas (analytical, necessary judgments) and propositions that do not provide knowledge. As we shall see later, this dichotomy is directly derived from the assumption that questions of value and questions of reason cannot be mixed, thus giving life to "Hume's scissors", an argument that here becomes important insofar as it becomes the last dichotomy we will consider in the next Sect. 2.4 of this article: the logical distinction between facts and values.

Considering that there are pure objects of knowledge and, at the same time, not abandoning the well-tempered scientific skepticism of Hume's empiricism is the gap that allowed Kant to found a transcendental philosophy that was critical at the same time. Thus, the problem for Kant was not whether or not it is possible to have metaphysical

\footnotetext{
7 It is not usual to relate universal linguistic projects to the epistemic question of the debate in the philosophy of science. However, this paper is not intended to address whether, in Begriffsschrift, Frege believed he had offered a complete view of reality, but rather whether to begin this enterprise, he needed to postulate the dichotomy between psychology and logic.
} 
knowledge but the epistemic value of epistemic operations, as this relation is detached from sensibility. Thus, as well-known, Kant sets limits to metaphysics, but these limits are prescriptive, also called regulative. In this way, a theory was founded that guaranteed the sensible knowledge defined by Hume and, at the same time, allowed that which is detached from experience to give meaning (not knowledge) to our reality. In other words, this opens the doors to critical rationalism (Kant, 1998: A 855/B 883).

The new critical spirit opens many doors. Kant says:

[...] it must still remain a scandal to philosophy and to the general human reason to be obliged to assume, as an article of mere belief, the existence of things external to ourselves (from which, yet, we derive the whole material of cognition for the internal sense), and not to be able to oppose a satisfactory proof to any one who may call it in question (Kant, 1998: B, Preface, xxxix).

This sentence is crucial for us. As we shall see in the third section, the way Frege interpreted it marked a radically different line of research; having followed Peirce's interpretation would have generated different results. One of the most exciting difficulties in the $\mathrm{Kr} V$ is precisely to bring the universal categories of the understanding into an agreement with those of sensibility, or, in other words, to explain the process by which we extract a general rule from sensible multiplicity. Kant finds the answer through a structural concordance between the categories of each of the stages, which forces him to confront the antinomy of the-pure-reason that is generated by causality, a problem that began precisely with empiricism.

This solution can be understood as a sophisticated version of the one offered by Leibniz in the Nouveaux essais sur l'entendement humain when he posed the relation between axioms and sensible knowledge. Leibniz's answer aims at establishing a dialectical type of relation, in which the axiom is extracted as a general rule (heuristic) which is confirmed through experience. Ergo, we will only know from particular cases. However, once we are situated through experience, regularities are understood as universalizable rules. This is possible through the concordance between the different sciences, from the highest to the lowest, which makes it possible to confirm something, here or there, and increase sensible knowledge and, at the same time, the universal (Leibniz, 1996: Bk. IV, Ch. 12). However, Kant's problem is substantially different from Leibniz's one, for he must redo the one that Hume's critique dismantles.

This solution affects formal knowledge. Therefore, as is well known, Kant theoretically resolves the tension between what he will call analytic judgments and synthetic judgments since the latter will have to adapt to the former formally. From this perspective, sensibility (contingency) is the foundation of knowledge and understanding the possibility of doing science. In this theoretical framework, Kant's claim arises because the tension between theory and praxis remains. As we shall see below, this not-solved tension is the starting point of both Peirce and Frege.

Finally, although heterogeneous, the rest of the propositions were put in the same category (questions of value, psychological factors, metaphysical, etc.). As they had no meaning since Wittgenstein's Tractatus (they were nonsense), they had no psychological value in the case of metaphysical propositions. Therefore, they were understood in the Kantian way as concepts regulating practical life. As is well known, the most forceful critique of the analytic/synthetic dichotomy was formulated by Quine from a pragmatist semantic holism in his Two Dogmas of Empiricism. Quine argues that the fact that 
an analytic judgment is tautological and the convention in the theory of meaning that allows these truths to be true in themselves are a matter of experience.

\subsection{Forth dichotomy: Fact/value}

The fact/value dichotomy declares the biconditional impossibility of inferring prescriptive propositions from descriptive ones. One of its technical names is the naturalistic fallacy coined by Moore. According to Putnam's (2002: 14-22) interpretation, such a dichotomy is the sophisticated transformation of Hume's Is-ought problem (2007: Bk. III, Ch. I, Sect. I). The point of view identifies this dichotomy with Kant's concern to automate ethics (Zammito, 2012: 307). Nevertheless, it is relevant to return to Hume's analysis because of its close relation to the analytic/synthetic dichotomy introduced in the previous section. Hume considered ethical propositions to be synthetic because they could be true or false. After all, they were to be verified by-and in-experience, in contrast to analytic propositions, conceived of as universal truths because of their logical form (analyticity).

It is important to note that there is an attempt to separate questions of fact from the relation of ideas in Hume's and Kant's theory, but ethics remains a more important question of all. In contrast, the positivists realized the process of logicization through the devaluation of ethics in knowledge matters, which would be understood as formalizable descriptions. However, this rejection stemmed from the psychological characterization of propositions (and ethical facts for that matter) as not formalizable, ergo not discernible.

To the extent that our worldview assumes that reality is vaster than our capacity to know it, this tendency to dichotomize has become detrimental because we need more adaptable systems that contemplate how we live the experience. As Putnam said, the reason this dichotomy is assumed is that it is understood as rational, where rationality is defined as the pursuit of objectivity intended as a verification tool to approach truth.

As is well known, pragmatism presents itself as an alternative because it assumes no separation between facts and values. Considering "a world of pure experience," values directly affect normativity in the sense of imposing simplicity, economy, plausibility, etc., all concepts that regulate how things ought to be (Putnam, 2002: 31). In other words, the description process cannot exhaust objectivity (ibid.: 33). Therefore, Putnam argues that a revision of metaphysics is necessary, in the sense that it has to become a new system that does not tend to deflate or inflate the ontology that shapes our reality but understands dichotomies as theoretical distinctions (ibid.: 9-13).

On the one hand, still following Putnam's theory, pragmatism understands experience as a non-neutral process because humans participate in the world in which each of us is an entity with motivations, dreams, and ideas about how reality could be (Putnam, 2002: 103). A good general characterization for this version of pragmatism might go like this: there is no epistemological difference between the truth about what ought to be and the truth about what is, nor any metaphysical difference between facts and values, nor any methodological difference between morality and science (Rorty, 1991: 163-164).

\section{Peirce's Interpretation of Kant's Claim}

As we have seen up to this point, the problem of the justification of synthetic a priori knowledge detected by Kant initiates a tradition of confronting the question by postulating dichotomies. The synthetic a priori judgment is born as a transcendental-theoretical tool 
after Kant had undone the "Hume's psychologizing of knowledge" (Cavell, 2002: 91). As already been explained, the dichotomy between psychological and logical facts is based on another more fundamental one: distinguishing between analytic and synthetic. Thus, although Kant was very clear that there could be no knowledge without experience and vice versa ("Thoughts without content are empty, intuitions without concepts are blind," Kant, 1998: A51/B75), his initial starting point implied a metaphysical approach to the question of sensible knowledge, but without being able to account for what sensibility was. Therefore, all those who carried out their research based on Kant's conclusions tended to perpetuate and radicalize this separation. Not surprisingly, most of these investigations gave more weight to the processes and results of logic and formal science.

Another solution to the problem of the justification of transcendental aesthetics is Peirce's recovery and translation of the Aristotelian $\dot{\alpha} \pi \alpha \gamma \omega \gamma \eta$ (apagōgē) (Aristotle, 1957: An. Pr. II 25, 69a20-35) as abduction (Peirce, 1958: 5.14-40). ${ }^{8}$ To answer Kant's question about how synthetic a priori judgments are possible, Peirce attempts to answer the earlier problem of how synthetic reasoning, in general, is possible (Peirce, 1958: 5.348). Peirce identifies abduction with the reasoning of open, hypothetical approximation of experience in reality: the mechanism by which hypotheses are generated, a concept that he understands as the fact of inferring with probability or making a reasonable conjecture (CP, 2.619-644). The same text exposes the famous syllogism concerning beans in a bag, comparing it with the versions that configure induction and deduction.

The best way to work on the matter is to synthesize some of Peirce's general ideas, for he will never finish polishing his concept of abduction. First, Peirce locates hypothesis, the inference to reasonable conjectures, in those circumstances in which something surprises us, and consequently, we generate a supposition (1958: 2.619-644). Peirce was twenty years old when Darwin's studies were published, and it is not very easy to think that this did not influence his intellectual life. Darwin ushered in a turbulent period, which went beyond the scientific community's debates over the possibility of the emergence of new science. However, as it is well known, the first conflict caused by the concept of "evolution" was the one of faith. As is well known, much of the controversy arose over the possibility of doubting the Genesis account.

Considering God as a valid hypothesis for science is not a postulate that can be made scientifically, but only as a religious belief. Nevertheless, as is well known, the proposal of evolution acquired relevance and was used to confirm other theories, such as the dating of the earth (I refer to the influence of Lyell's work on Darwin). This shows that the real problem was not in the change of interpretation of the physical world but in doubt installed in the related worldview: in the social and cultural subsumption of that worldview. ${ }^{9}$ I am referring to questions concerning morality and the existential reason for being, and the purpose of living.

This interrelation between science and society is found in Darwin's first sketches of his theory of evolution. I am referring to his reading of Malthus' theses regarding the analysis of the uncontrolled growth of populations, the social brakes on this happening,

\footnotetext{
$8 \mathrm{CP}$ is the internationally recognized abbreviation for Peirce's Collected Papers.

9 I use "cosmovision" to refer to the unified picture of the two types of interpretations of the world generated by human agents: the biological and the sociocultural. The former is each agent's perception and conceptualization of the environment, and the latter is the result of participation in public life. Considering that the socio-cultural interpretation comprises the biological one, it can be identified with the name "cosmovision", while I refer to the biological one as "worldview" (c.f. Magnani et al., 2021, Sect. 1.1).
} 
and his comparison with nature. In other words, it was partly thanks to these readings, which were entirely directed at socio-economic issues, that Darwin began to devise the concept of species (Gilson, 1984: 74-80). Applied to the human being, this concept also comes into conflict with all cultural aspects, which are based on the idea that humanity is a privileged and finalized project. In relation to pragmatism, not enough emphasis has been placed on the weight of evolutionary theory in the renewal of understanding the human being. As West says, pragmatism has a very specific way of vindicating the subject: distancing itself from structuralism and humanism:

This focus on powers has returned humanistic studies to the primal stuff of human history, that is, structured and circumscribed human agency in all its various manifestations. Gone is the once fashionable poststructuralist claim to eliminate the subject. Yet also gone is the old humanist view that elevates the human agency of elite cultural creators and that ignores social structural constraints, constraints that reinforce and reproduce hierarchies based on class, race, gender, and sexual orientation. It is no accident that American pragmatism once again rises to the surface of North Atlantic intellectual life at the present moment. For its major themes of evading epistemology-centered philosophy, accenting human powers, and transforming antiquated modes of social hierarchies in light of religious and/ or ethical ideals make it relevant and attractive. The distinctive appeal of American pragmatism in our postmodern moment is its unashamedly moral emphasis and its unequivocally ameliorative impulse. In this world-weary period of pervasive cynicisms, nihilisms, terrorisms, and possible extermination, there is a longing for norms and values that can make a difference, a yearning for principled resistance and struggle that can change our desperate plight (West, 1989: 4).

For Peirce, science will reflect the fact that we are constantly adapting ourselves to new circumstances, and this can only happen by focusing attention on the structures that shape scientific explanations, namely language. This conception is based on the evidence that it is impossible to adapt through "reason" based on a rigid and closed idea of the world. In other words, knowing the world is an open project in which we participate actively, completing it to the extent that we experience it and then take it in. Peirce's proposal deals with the icon of language. As is known, Peirce's semiotics is broken down into a triad composed of the symbol, which is understood as a linguistic representation of similarities, the index, and the icon. By "resemblance," Peirce means the type of iconic representation that occurs between the signs and that which they signify (Dipert, 1996: 373). The essential characteristic of resemblance lies in its potential to appear similar to things we are not familiar with from the icon. If we start from what this element is the most relevant part of the structure of language, all logical reasoning is iconic and, therefore, operates prima facie with this potentiality.

I refer to this particular form of hypothetical reasoning in an environment of a constant flow of information as a proliferation of experiences, controlled precisely by the pragmatic postulate, which, while on the one hand, considers all knowledge of itself to have the status of a constant hypothesis, on the other hand, the possible experience is limited by the Kantian transcendental categories, which, although in Peirce are interpreted from the postulates of practical reason, remain detached from a naturalistic interpretation (Apel, 2016: 28-29). This way of understanding the processes of acquiring/ generating experience is constituted on the fallibilist approach of critical realism of the 
pragmatic perspective in which continuous experience is conceptualized "through the icon" and controlled by the postulates of pure reason.

This proliferation of experiences has its cornerstone, the abduction, which functions for the Reason as a logical constrictor. The pragmatic point of view offers a naturalized interpretation of these processes, which makes possible the generated hypotheses and, on the other hand, to choose one or limit the number of possibilities. For Peirce, along with deduction (first reasoning) and induction (second reasoning), abduction constitutes the third reasoning, lost in the course of history, by which the appeal to instinct can be accounted for:

Reasoning is of three kinds-the first is necessary, but it only professes to give us information concerning the matter of our own hypotheses and distinctly declares that, if we want to know anything else, we must go elsewhere. The second depends upon probabilities. The only cases in which it pretends to be of value is where we have, like an insurance company, an endless multitude of insignificant risks. Wherever a vital interest is at stake, it clearly says, "Don't ask me." The third kind of reasoning tries what il lume naturale, which lit the footsteps of Galileo, can do. It is really an appeal to instinct. Thus reason, for all the frills it customarily wears, in vital crises, comes down upon its marrow-bones to beg the succor of instinct (Peirce, 1958: 1616-648).

What interests us here is the third type of reasoning. It is interesting because it makes an explicit reference to abduction and because this quotation shows how this reasoning is related to the practical dimension. As will be recalled, in Kant's philosophy, the transcendental ideas of reason do not imply any knowledge. Instead, their exclusively immanent use gives them the status of regulating principles of reason, allowing reflective judgment toward that which is beyond experience (Kant, 1998: B 384). Here, the organizing and systematizing aspect of the knowledge of regulative ideas is of interest, making it possible to think the object beyond experience through reasoning (ibid.: B 673). Therefore, as an enabler of the moral law through its constitution, postulates of practical reason (Kant, 1998: 5:133). This is Peirce's starting point, who puts forward the idea that a hypothesis is a weak argument, not in the Aristotelian sense of validity, but in a sense closer to the rhetorical image of the reed bent by the wind, which can touch for a few moments other places that the tree cannot even imagine. In other words, it allows us to make iconic relations that generate one or more conjectures.

It is very likely that Peirce already had in mind here the problem of the generation and selection of more or less reasonable conjectures. As we shall see, this is a fundamental problem in the temporal debate, for it is not the same thing to say that the regulation of abduction is proper to abduction itself, as to say that this verification is of an inductive type. However, Peirce is more concerned with the generation of knowledge than with the technical aspects since they appear as a circumstantial and methodical question of which he does not have to give an account. This becomes clearer when he speaks of the phenomenological aspects of this process. From this perspective, he introduces the psychological notion of the surprise of experiencing something unexpected, which he understands as the accent that predisposes our state of consciousness when an unthought-of imaginary object is presented to our consciousness (Peirce, 1958: 5.41-56, 59-65). Thus, the interplay between knowing and not knowing, the surprise about what we know, is at play here.

What allows Peirce to go a step beyond the problems of hypothesis adequacy, verification, etc., is his realization that the generation of a conjecture occurs through the semiotic 
process of transforming experience into concepts. In other words, knowledge is built on the shifting sands of conjecture. This is why one of Peirce's greatest contributions has been the characterization of doubt and the different mechanisms by which it is mitigated. For example, through the grounding of belief (Peirce, 1958: 5.358-387). The pragmatist approach to these questions involves reevaluating these concepts to give them an epistemological status in the grounding of knowledge.

In Peirce's theory, there is also a conjunction between perception and understanding when a distinction is made between what is called "corollary" knowledge, that is, the knowledge that stands on its own, and what is called "theorematic" knowledge, or, in other words, the knowledge that needs auxiliary elements to be proved. Both concepts come from geometry, and the reason is that in Peirce we find a very refreshing reflection on the geometrical theme. Peirce proposes that mathematics and geometry are built on diagrams of general precepts (Magnani, 2001: 171). This is to be understood under the focus of semiotics. The possibility of understanding diagrams in this way lies in the relation of iconic similarity with which logic operates. Thus, the auxiliary elements for the theoretical verification lie in semiotic similarity, in a structural sense of geometrical forms (Hintikka, 1998: 233). It must be understood that this cognitive process also allows the fact that counterexamples can be raised, not only from experience but also by abstraction. A proof can be understood as the construction of a counterexample and, in this sense, the simple fact demonstrates what is logically (semiotically) possible.

\section{A Fundamental Problem of Philosophy: The Intertwining Between Theory and Praxis}

Abduction and pragmatism have to be seen as co-dependent because they derive from the same origin. This dependence has been blurred throughout history because of the complicated evolution of the various concepts of pragmatism to the point that abduction has not been considered necessary in the case of various philosophical perspectives inspired by pragmatism. However, this fact can also be seen by reading between the lines on abduction in contemporary debates. Often, this concept is used as a panacea to solve classical problems in which it does not even participate.

As mentioned above, those philosophers who used abduction for their arguments ended up constituting the neglected view of science. Of all those presented, Hanson goes explicitly back to Peirce (Gabbay \& Woods, 2005: 104-109; Niiniluoto, 1999: S440-441). For Hanson, abduction or retroduction (Hanson, 1972: 85) does not always lead to synthesis [...], but "sometimes shows the first chink in the old armour" (Hanson, 1972: 124-1n). What Hanson means is that "physicists rarely find laws by enumerating and summarising" but, at the same time: "physicists do not start from hypotheses; they start from data". Thus, "the inductive view rightly suggests that laws are got by inference from data [,] it wrongly suggests that the law is but a summary of these data, instead of being what it must be, an explanation of the data" (ibid.: 70-71).

In this sense, Hanson (and Feyerabend) agree that there are "observational meanings" that are more relevant than others. While Hanson states that: "There is a sense, then, in which seeing is a 'theory-laden' undertaking" (Hanson, 1972: 19), Feyerabend further observes that: "On closed analysis we even find that science knows no 'bare facts' at all but that the 'facts' that enter our knowledge are already viewed in a certain way and are, therefore, essentially ideational" (Feyerabend, 2010: 3). Leaving aside the contrast between 
Hanson's semantic perspective and Feyerabend's epistemological one, the common ground is the following: discovery is brought about by factors external to justification, including a myriad of processes. Feyerabend added that if these processes are contemplated, then the scientific method advocated in the philosophy of science is shown to be false.

Inspired by the ideas of the philosophers of the neglected view of science quoted in Sect. 2.1, it could be argued that both their critique and their invocation of pragmatism are responses to the question of the relationship between theory and praxis within scientific research. As we have seen, the relationship between the practice of research and the overlapping of the dimensions considered dichotomous is based on the foundations of Peirce's pragmatist theory. The neglect of this reality is mainly due to two factors. On the one hand, the particular development of pragmatism (the biased selection of Peirce's work) and on the other hand the critique of James psychologistic pragmatism (which placed the humanist challenge above systematization). Russell points to this idea in the section devoted to James in his History of Western Philosophy (Russell, 1945: 812). Russell had a heated debate with James through different publications, in which James criticized him for reducing pragmatism to absurdity because he did not understand that evaluation and description were intertwined (James, 1991a: Sect. XIV: 962-968).

The dissonance between theory and praxis can be understood even better from the two distinctions made by Feyerabend: the distinction between the questions of the observer and those of the participant (Feyerabend, 1978: 18) and the distinction between a paradigm and a surprising fact (Feyerabend, 1967: 401). It is possible to identify the observer's questions with the philosophers, who are the ones who pose the questions based on data that the participants cannot have. As already explained, philosophers understand current scientific practice from history experiments, successes, and failures related to anomalies. On the other hand, the participant's questions are those asked by the scientists in the scientific practice.

During these processes that make up research, there is a constant connection between theory and practice to account for phenomena that never fit together (constant discoveries). Thus, the historical perspective from which the philosopher asks the questions does not fit the present time in which the research takes place. Therefore, the facts understood as paradigmatic from a historical perspective are always surprising for the participant. Note that, from this perspective, it is not relevant whether the event is paradigmatic or not (it is always surprising to one degree or another), but whether the observer's questions are crucial for the participant. Thus, the solution to the classical problem of the relationship between theory and praxis is given through a change of cosmological perspective that assumes an open and inconclusive conception of the world.

Like Marxism and Existentialism, pragmatism is a philosophy that attempts to situate the human being in a world that is now understood to be inconclusive. In this sense, the mediation between theory and praxis is an attempt to account for the uncertainty of the future (Apel, 2016: 11). However, although these approaches may share the concerns of the same epoch, these did not incite the same philosophical concerns. As seen in the previous section, Peirce initiates pragmatism to answer the epistemological question of the grounding of sensible knowledge. His answer situates abduction as the continuous mechanism of open and hypothetical approximation of knowledge controlled by the criteria of adaptation to the environment. Thus, for Peirce, investigation (knowing) implies a constant and controlled approach to reality (Apel, 2016: 29-30).

However, the teleological idea of arriving at truth, in the long run, is determined by the different ways of adapting to the environment through praxis. This incorporates in the research process elements that account for the different ways in which we control the 
uncertainty of becoming. In this sense, pragmatism affirms that inquiry is vitally linked to the human condition: our actions are ontologically constitutive of the world. Therefore, the world that science investigates is also the moral world we construct and live in (James, 1991b: 604-605). Likewise, the idea of progress, result (justification), etc., are eclipsed by the relevance of personal experience before the cases we live as problematic and, therefore, before the primacy of the motivations, interests, beliefs, and culture that guide our actions (Feyerabend, 1999: 28-29).

\section{Conclusion}

In this article, I have argued that many parts of the contemporary philosophical debate have been built on the radicalization of conclusions derived from accepting a particular set of tradition-derived dichotomies. This article aims to analyze the impact of this fact on the philosophy of science and logic. In order to explain the role of pragmatism in the dissolution of philosophical dichotomies, I have drawn on the analysis of the case of abductive reasoning. Indeed, on the one hand, this concept is increasingly critical, and, on the other hand, it underlies the philosophical perspective of pragmatism. I have emphasized that the use of abduction implies in many ways the partial or complete acceptance of pragmatist theory. From this philosophical perspective, abduction is understood as a mechanism of hypothetical and continuous approximation to the reality that makes it possible to account for circumstances in which the resolution of a problem come hand in hand with the postulation of a hypothesis that posits a possible actualization of the world.

I have also stressed that the reencounter of this theory with its current foundational concepts implies accepting a way of doing philosophy that denies the dichotomies that have served to structure contemporary debate. This has been seen through the involvement of valuational elements in research by reconciling of theory and praxis when a hypothesis determines a line of action towards uncertainty. In this perspective, abduction must be seen as the correct conceptual device capable of favoring revisiting the problems and debates of the past century that shaped the standard view of the twentieth-century philosophy of science.

Funding Open access funding provided by Università degli Studi di Pavia within the CRUI-CARE Agreement. Research for this article was supported by the PRIN 2017 Research 20173YP4N3-MIUR, Ministry of University and Research, Rome, Italy.

\section{Declarations}

Conflict of interest The corresponding author states that there is no conflict of interest.

Open Access This article is licensed under a Creative Commons Attribution 4.0 International License, which permits use, sharing, adaptation, distribution and reproduction in any medium or format, as long as you give appropriate credit to the original author(s) and the source, provide a link to the Creative Commons licence, and indicate if changes were made. The images or other third party material in this article are included in the article's Creative Commons licence, unless indicated otherwise in a credit line to the material. If material is not included in the article's Creative Commons licence and your intended use is not permitted by statutory regulation or exceeds the permitted use, you will need to obtain permission directly from the copyright holder. To view a copy of this licence, visit http://creativecommons.org/licenses/by/4.0/. 


\section{References}

Apel, K-O. (2016). Der Denkweg von Charles S. Peirce. Eine Einführung in den amerikanischen Pragmatismus. Suhrkamp Verlag.

Aristole. (1957). Analytica Priora et Posteriora (W. D. Ross, ed.). Oxford University Press.

Bäckström, S. (2017). What is it to depsychologize psychology? European Journal of Philosophy, 25, 358375. https://doi.org/10.1111/ejop.12213

Bergman, M. (2012). Pragmatism as a communication-theoretical tradition: An assessment of Craig's proposal. European Journal of Pragmatism and American Philosophy, 4(1), 208-221.

Boden, M. (2004). The creative mind: Myths and mechanisms. Routledge.

Brown, M. J. (2020). Pluralism and perspectivism in the american pragmatist tradition. In A. M. Crețu \& M. Massimi (Eds.), Knowledge from a Human point of view (synthese library (studies in epistemology, logic, methodology, and philosophy of science) (pp. 37-56). Springer.

Butterfield, H. (1965). The whig interpretation of history. The Norton Library.

Cavell, S. (2002). Aesthetic problems of modern philosophy. In must we mean what we say? A book of essays (pp. 73-96). Cambridge University Press. https://doi.org/10.1017/CBO9780511811753.006.

Cooren, F. (2014). Pragmatism as ventriloquism: Creating a dialogue among seven traditions in the study of communication. Language under Discussion, 2(1), 1-26. https://doi.org/10.31885/lud.2.1.239

Dipert, R. (1996). Reflections on iconicity, representation, and resemblance: Peirce's theory of signs, goodman on resemblance, and modern philosophies of language and mind. Synthese, 106(3), 373-397.

Fernández Buey, F. (2004). La ilusión del método. Ideas para un racionalismo bien temperado. Editorial Crítica.

Feyerabend, P. K. (1967). On the Improvement of the Sciences and the Arts, and the Possible Identity of the Two. In: Cohen R.S., Wartofsky M.W. (Eds), Proceedings of the Boston Colloquium for the Philosophy of Science 1964/1966 (Boston Studies in the Philosophy of Science, vol 3., pp. 387-415). Springer. https://doi.org/10.1007/978-94-010-3508-8_22.

Feyerabend, P. K. (1978). Science in a free society. Lowe \& Brydone Ltd.

Feyerabend, P. K. (1999). Farewell to reason. Verso.

Feyerabend, P. K. (2010). Against method. Verso.

Frege, G. (1956). The thought: A logical inquiry. Mind, 65(259), 289-311.

Gabbay, M., \& Wood, J. (2005). A practical logic of cognitive systems: The reach of Ab-duction-Insight and trial. Elsevier.

Gilson, E. (1984). From Aristotle to Darwin and Back Again: A Journey in Final Causality, Species, and Evolution (transl. University of Notre Dame Press.

Hanson, N. R. (1972). Patterns of discovery. Cambridge University Press.

Hanson, N. R. (1973). Constellations and conjectures. D. Reidel Publishing Company.

Harman, G. (1965). The inference to the best explanation. Philosophical Review, 74(1), 88-95.

Hesse, M. (1954). Science and the human imagination: Aspects of the history and logic of physical science. SCM Press.

Hesse, M. (1966). Models and analogies in science. Notre Dame University Press.

Hintikka, J. (1998). What is abduction? The fundamental problem of contemporary epistemology. Transactions of the Charles S. Peirce Society, 34(3), 503-533.

Hintikka, J. (2007). Socratic epistemology. Cambridge University Press.

Hume, D. (2007). An enquiry concerning human understanding. Oxford University Press.

Hume, D. (2009). A treatise of human nature. The Floating Press.

Huxley, A. (1948). Time must have a stop. London: Chatto \& Windus.

James, W. (1991b). The will to believe and other essays in popular philosophy. In psychology: Briefer course, the will to believe, talks to teachers and to students, essays (pp. 445-704). Library of America.

James, W. (1991a) The meaning of Truth. In William James: Writings 1902-1910: The Varieties of Religious Experience, Pragmatism, A Pluralistic Universe, The Meaning of Truth, Some Problems of Philosophy, Essays (pp. 823-978). Library of America.

Kant, I. (1998). Critique of Pure Reason (transl Paul Guyer \& Allen W Wood). Cambridge University Press.

Kant, I. (2015). Critique of practical reason (transl. Mary Gregor). Cambridge University Press.

Kieseppa, I. (1996). Truthlikeness for Multidimensional Quantitative Cognitive Problems. Synthese.

Kluge, E. (1980). Frege, leibniz and the notion of an ideal language. Studia Leibnitiana, 12(1), $140-154$.

Kuipers, T. (2000). From Instrumentalism to Constructive Realism. On some Relations between Confirmation, Empirical Progress and Truth Approximation. Synthese Library.

Lakatos, I. (1978). The methodology of scientific research programmes: philosophical papers. Cambridge University Press. 
Laudan, L. (1980). Why was the logic of discovery abandoned? In Thomas Nickles (Ed.), Scientific discovery, logic and rationality (boston studies in the philosophy and history of science) (pp. 173-183). Kluwer Academic Publishers.

Leibniz, G. W. (1996). New essays on human understanding (transl. Peter Remnant \& Jonathan Bennett). Cambridge University Press.

Łukasiewicz, J., \& Wedin, V. (1971). On the principle of contradiction in aristotle. The Review of Metaphysics, 24(3), 485-509.

Magnani, L. (2017). The abductive structure of scientific creativity. Springer.

Magnani, L. (2001). Philosophy and geometry. Kluwer Academic Publishers.

Magnani, L. (2007). Logic and abduction: Cognitive externalizations in demonstrative environments. Theoria, 60, 275-284.

Magnani, L. (2014). Abductive cognition. Springer.

Magnani, L. (2019). AlphaGo, locked strategies, and eco-cognitive openness. Philosophies, 4(1), 8. https:// doi.org/10.3390/philosophies4010008

Magnani, L., Pinillos, A. S., \& Arfini, S. (2021). Language: The "ultimate artifact" to build, develop, and update worldviews. Topoi. https://doi.org/10.1007/s11245-021-09742-5

Mill, J. S. (2002). A system of logic. University Press of the Pacific.

Müller, V. C., \& Hoffmann, M. (2017). What is morphological computation? On how the body contributes to cognition and control. Artificial Life, 23(1), 1-24. https://doi.org/10.1162/ARTL_a_00219

Musgrave, A., et al. (1989). Deductive heuristics. In K. Gavroglu (Ed.), Imre lakatos and theories of scientific change (pp. 15-32). Kluwer Academic Publishers.

Niiniluoto, I. (2014). Representation and truthlikeness. Foundations of Science, 19(4), 375-379.

Nöhler, E. (2004). Physical Intuitions as Inductive Support. In F. Stadler (Ed.), Induction and deduction in the sciences (pp. 151-168). Springer.

Peirce, C. S. (1958). In C. Hartshorne \& P. Weiss (Ed.), Collected papers of charles sanders peirce (Vol. 1-6). Cambridge: Harvard University Press, 1931-1935; (Vol. 7-8) (A.W. Burks Ed.). Harvard University Press.

Putnam, H. (2002). The collapse of the fact/value dichotomy. Harvard University Press.

Quine, W. V. O. (1961). Two dogmas of empiricism. From a logical point of view (pp. 20-46). Harper \& Row Publishers.

Reichenbach, H. (1951). The rise of scientific philosophy. University of California.

Rorty, R. (1991). Objectivity, relativism, and truth: Philosophical papers. Cambridge University Pres.

Russell, B. (1945). The history of western philosophy. American Book-Stratford Press, Inc.

Sans, A., \& Casacuberta, D. (2019). Remarks on the possibility of ethical reasoning in an artificial intelligence system by means of abductive models. In Á. Nepomuceno-Fernández, L. Magnani, F. SalgueroLamillar, C. Barés-Gómez, \& M. Fontaine (Eds.), Model-based reasoning in science and technology MBR 2018: Studies in applied philosophy, epistemology and rational ethics. Springer.

Simon, H. A. (1985). Psychology of scientific discovery. Paper presented at the 93rd Annual APA Meeting, Los Angeles, CA.

Simon, H. A., Valdés-Pérez, R. E., \& Sleeman, D. H. (1997). Scientific discovery and simplicity of method. Artificial Intelligence, 91, 177-181.

Sundin, O., \& Johannisson, J. (2005). Pragmatism, neo-pragmatism and sociocultural theory: Communicative participation as a perspective in LIS. Journal of Documentation, 61(1), 23-43. https://doi.org/10. 1108/00220410510577998

Thagard, P. (1988). Computational philosophy of science. MIT Press.

West, C. (1989). The American evasion of philosophy: A genealogy of pragmatism. The University of Wisconsin Press.

Woods, J. (2013). Errors of reasoning. College Publications.

Zammito, J. H. (2012). The "Last Dogma" of positivism: Historicist naturalism and the fact/value dichotomy. Journal of the Philosophy of History, 6(3), 305-338. https://doi.org/10.1163/18722636-12341 235

Publisher's Note Springer Nature remains neutral with regard to jurisdictional claims in published maps and institutional affiliations. 
Alger Sans Pinillos in the framework of the "Training Program for University Teachers Grant-(FPU2015)", has been Predoctoral Fellow at the Dept. of Philosophy of the Autonomous University of Barcelona, where he carried out and earned a Ph.D. in Cognitive Science and Language with research on the prescriptive aspects of abductive reasoning. Currently, he is a Postdoctoral Fellow of Philosophy of Science (program "Understanding the Limits of Cognition: uncertainty, abduction, creativity, naturalization of irrationality and ordinary reasoning, computational domestication of ignorant entities") at the Dept. of Humanities-Philosophy Section of the University of Pavia, Italy. 